\title{
Afferents to the Midbrain Auditory Center in the Bullfrog, Rana catesbeiana
}

\author{
WALTER WILCZYNSKI
}

Neurosciences Program, University of Michigan, Ann Arbor, Michigan 48109

\begin{abstract}
Horseradish peroxidase (HRP) histochemistry was used to visualize cells afferent to the bullfrog torus semicircularis. These afferent cells are located in several sensory and nonsensory nuclei. The sensory structures which project to the torus are mainly auditory nuclei, with the major input coming from the ipsilateral superior olive. A very small contralateral projection is also present. In addition, afferents arise from the contralateral, and to a lesser extent ipsilateral, dorsal acoustic nucleus and nucleus caudalis, both primary eighth nerve nuclei. A vestibular input is also apparent in that HRP-positive cells were seen in the magnocellular vestibular nucleus and among elongated bipolar cells at the ventral border of the eighth nerve nuclei. In addition, the torus receives somatosensory input from the contralateral perisolitary band. Afferents from spinal cord cells proved difficult to visualize. Nonsensory areas throughout the brain innervate the torus as well. In the medulla, HRP-positive cells were present bilaterally in both medial and lateral reticular areas. The tegmentum contributes a major input from the superficial isthmal reticular nucleus and a minor input from the tegmental fields. Commissural toral projections are also present. Descending forebrain input arises from the pretectal gray bilaterally, the ventral half of the ipsilateral lateral pretectal nucleus, and, possibly, from the ipsilateral posterior thalamic nucleus. HRP-positive cells were also occasionally seen in the posterior tuberculum, ventral hypothalamus, and caudal suprachiasmatic preoptic area. Finally, a telencephalic projection from the ipsilateral anterior entopeduncular nucleus is present.
\end{abstract}

Acoustic signaling plays a significant, even dominant, role in the social behavior of anuran amphibians. It is important to individuals for mate selection and the maintainance of breeding aggregations, and is crucial to the species as a whole in insuring reproductive isolation (Blair, '58). To date, physiological studies have shown several areas of the anuran central nervous system to be involved in auditory processing (for review, see Capranica, '76). The largest of these areas lies in the mesencephalon, and, as in other nonmammals, is termed the torus semicircularis.

The anuran torus semicircularis is a large, well-developed portion of the midbrain roof homologous to the mammalian inferior colliculus and similar midbrain roof areas in other vertebrates (Ariëns-Kappers et al., '60). Toral association with the auditory system is well-established physiologically (Potter, '65; LoftusHills, '71; Capranica, '76) and experimental anatomical studies have shown a heavy input from the medullary auditory areas (Fuller and
Ebbesson, '73; Rubinson and Skiles, '75). However, the torus also receives somatosensory (Ebbesson, '76) and hypothalamic (Neary and Wilczynski, '77b) inputs. These additional afferents suggest that, like the mesencephalic portion of the visual system, the optic tectum, the torus is not a simple relay nucleus but rather an important sensory integration center. As such, the torus might have a range of afferents similar to the optic tectum, which receives several sensory and nonsensory inputs presumed to modulate its sensorimotor functions (Trachtenberg and Ingle, '74; Wilczynski and Northcutt, '77). Information about toral connections is too sparse to determine if this hypothesis is correct. There is as yet no full appreciation of the total pattern of toral connections. Auditory and some nonauditory inputs have been described, but in no case have the cells of origin been precisely identified.

Walter Wilczynski's present address is Cornell University, Section of Neurobiology and Behavior, Ithaca, New York 14853 
A thorough description of toral afferents would determine whether a wide range of afferents converge on this midbrain auditory center, and it would generate hypotheses about how the torus functions in auditory processing. Moreover, an anatomical study of the torus would yield an appreciation of the overall pattern of anuran auditory circuits. In mammals, the inferior colliculus receives both ascending inputs from brainstem auditory nuclei and descending inputs from forebrain auditory centers (Barnes et al., '43; Diamond et al., '69; Fitzpatrick and Imig, '78; Adams, '79) and possesses both ascending and descending efferents (Moore and Goldberg, '66; Carey and Webster, '71). In amphibians, the torus might occupy a similar nodal point in the central auditory pathways, and, if so, comparison with the mammalian condition could lead to an appreciation of the overall organization of the auditory system in this vertebrate class. With these goals in mind, a study of toral afferents using horseradish peroxidase histochemistry was undertaken.

A brief preliminary report of the results described in this paper was published previously (Wilczynski, '78).

\section{MATERIALS AND METHODS}

Twenty-five percent Sigma VI horseradish peroxidase (HRP) in distilled water was pressure-injected into the torus semicircularis in a total of 15 adult Rana catesbeiana anesthetized with MS 222. A dorsal approach was employed in 13 animals. A skin flap was opened over the skull and the underlying bone removed with a dental drill. The meninges were removed to expose the optic tectum. A glass injection pipette was either driven through the tectum into the underlying torus or placed directly into the torus after a small portion of the tectum was removed by aspiration. In two animals a ventral approach was used. The soft tissues in the roof of the mouth were incised and retracted and a hole drilled in the underlying ventral aspect of the skull. The meninges were removed and the pituitary carefully retracted. The injection pipette was driven through the exposed tegmentum into the torus. Injection volumes ranged from 50 to $200 \mathrm{nl}$. Following the injection the wounds were packed with Gelfoam and sutured.

Survival times ranged from 3 to 9 days at $23^{\circ} \mathrm{C}$. The optimal survival time was 5 to 6 days. The animals were then reanesthetized and perfused transcardially with $0.7 \%$ saline followed by a cold fixitive composed of $2 \%$ gluteralde- hyde- $30 \%$ sucrose in phosphate buffer $(\mathrm{pH} 7.4)$. The brains were removed and placed in cold fixitive for 3 to 6 hours, after which they were washed in cold phosphate-buffered ( $\mathrm{pH}$ 7.4) $30 \%$ sucrose overnight.

The brains were blotted dry, stripped of all adhering meninges and connective tissue, and embedded in $10 \%$ gelatin-30\% sucrose in distilled water. The block was trimmed and hardened in gluteraldehyde fixitive for 22 to 24 hours, then sectioned at $40 \mu \mathrm{m}$. The sections were collected in cold phosphate buffer.

The presence of HRP was demonstrated by two different methods. In the first, or brown, reaction, modified from Graham and Karnovsky ('66), sections were pretreated by placing them in $10 \%$ cobalt chloride for 30 minutes. After rinsing in distilled water, the sections were preincubated at room temperature in 30 $\mathrm{mg}$ per $100 \mathrm{ml}$ o-dianisodine in $\mathrm{pH} 7.4$ phosphate buffer for 5 minutes. Three to $7 \mathrm{ml}$ of $1.2 \%$ hydrogen peroxide was added and the incubation continued for an additional 7 to $25 \mathrm{~min}$ utes. Three 5-minute washes in distilled water followed. The sections were then mounted onto chrome-alum slides, counterstained with cresyl violet, dehydrated, cleared, and coverslipped.

The second, or green, reaction is based on the method of Colman et al. ('76). The reaction dishes were placed in an ice bath and the sections preincubated in a cold solution of $30 \mathrm{mg}$ o-dianisodine per $100 \mathrm{ml}$ of distilled water combined with $1 \mathrm{ml}$ of $10 \%$ nitroprusside. One to 5 $\mathrm{ml}$ of $1.2 \%$ hydrogen peroxide was added and the incubation continued for 5 to 15 minutes. The sections were rinsed in two 5-minute washes of $3 \%$ nitroprusside followed by an additional rinse in distilled water, then mounted, counterstained, dehydrated, cleared, and coverslipped.

\section{Control injections}

Three bullfrogs received unilateral tectal HRP injections. In two other animals, a ventral approach was used to inject HRP into the tegmentum. These control cases were processed as above.

\section{RESULTS \\ Injection sites}

Dorsal approach injections. Three of the 13 frogs injected using a dorsal approach died shortly after surgery. In one additional animal only a faint reaction occurred in the tectum and ependymal cells lining the tectal ventricle. This animal was used to control for inadvertent 
leakage of HRP into the ventricular system and tectum. Examination of this case revealed only a few HRP-positive cells in the dorsal pretectum and nucleus isthmi, and a few HRP-positive fibers in the ipsilateral optic tract, all of which can be accounted for by the HRP introduced into the tectum.

All of the remaining nine injections were centered in the torus. In every case some HRP was present in the overlying tectum, usually surrounding the pipette tract or ringing the edges of the aspirated tectal area. Most injections reached the dorsal edge of the tegmentum. However, two injections were very small and did not extend below the dorsal half of the torus.

Ventral approach injections. Both ventral approach injections involved extensive areas of the tegmentum as well as the torus. One involved equal areas of the torus and tegmentum while the other covered a number of nuclei at the diencephalic-midbrain junction. Neither injection site spread to the optic tectum.

\section{Interpretation of results}

Afferents to the torus were distinguished from those to adjoining areas by comparing the various cases of dorsal approach injections against one another and eliminating afferents which appeared solely dependent on tectal or teginental involvement. The pattern deduced was compared to results from the ventral approach injections, and to control injections confined to the tegmentum or tectum (including previously published material by Wilczynski and Northcutt, '77). A consistent pattern of HRP-positive cells distributed throughout the neuraxis thus emerged, which varied only quantitatively and seemed related only to the volume of HRP injected and the extent of toral involvement in the injection site. This pattern of toral afferents is charted in Figures 2 and 3 , with Figure 1 marking the positions of the levels charted.

\section{Toral afferents}

Medullary auditory centers provide the major input to the torus. A large number of HRP-positive cells were distributed throughout the ipsilateral superior olive (Fig. 2B). Both small pyriform-shaped cells and larger cells with thick, branching dendrites were filled with the reaction product (Fig. $4 \mathrm{~B}$ ). Very few contralateral olivary cells were filled. Additional auditory input arises from the contralateral, and to a lesser extent ipsilateral, dorsal medullary complex of VIII (Fig. 2B). All three eighth nerve nuclei (dorsal acoustic, ventral vestibular, and nucleus caudalis) project to the torus. Both the dorsal acoustic nucleus (Fig. 4A) and the nucleus caudalis contained large numbers of HRP-positive cells, while the number in the ventral division was small. Most of the ventral HRP-positive cells were elongated bipolar cells occupying the most ventral border of the vestibular division (Fig. 4C). Filled magnocellular cells were seen infrequently.

Fibers from the HRP-positive cells in the dorsal medullary complex of both sides converged into a thicket of HRP-positive fibers in the ipsilateral superior olive. Fibers from the contralateral cells crossed after passing through the reticular formation above the olive. A large bundle of HRP-positive fibers connected the ipsilateral olive with the torus. This bundle appears congruent with the tractus bulbolateralis, or lateral lemniscus, of Larsell (34). It occupied a ventral position in line with the olive until just rostral to the trigeminal motor nucleus, where it swung more dorsolaterally at successively rostral levels. After passing through the caudal superficial isthmal reticular nucleus the bundle entered the torus in a wide band extending from the level of the nucleus isthmi to the rostral torus.

HRP-positive cells were also seen bilaterally in the medial and lateral reticular formations at olivary levels. The medial reticular cells were concentrated immediately above the olive, and many possessed filled dendrites which extended ventrally, suggesting that these cells receive auditory input.

The HRP-positive cells in the nuclei at olivary levels were counted in the three largest toral injections (cases TSX-6, -9, and -15). The sums, shown in Table 1, indicate that the olivotoral projection is almost exclusively ipsilateral while afferents from the dorsal medullary complex are predominantly contralateral, but not as sharply skewed as the olivary afferents. Differences were also apparent among the reticular afferents. While most filled medial reticular cells were ipsilateral to the injection, filled lateral reticular cells were almost evenly distributed.

More caudally, at obex levels, HRP-positive cells were present in all three divisions of the contralateral perisolitary band (Fig. 2A), a cell plate dorsal and lateral to the tractus solitarius thought to have a somatosensory function (Neary and Wilczynski, '77a). Occasionally, filled fibers from the band could be seen sweeping ventromedially through the reticular nu- 


\begin{tabular}{llll}
\hline & & Abbreviations & \\
A & Anterior thalamic nucleus & MR & Medial reticular formation \\
AD & Anterodorsal tegmentum & NPM & Nucleus profundus mesencephali \\
AL & Lateral amygdala & nVIII & Eighth cranial nerve \\
AM & Medial amygdala & ON & Optic nerve \\
AV & Anteroventral tegmentum & OT & Optic tectum \\
C & Central thalamic nucleus & P & Posterior thalamic nucleus \\
DMc & Dorsal medullary complex of VIII, nucleus & PD & Posterodorsal tegmentum \\
& caudalis & PG & Pretectal gray \\
DMd & Dorsal medullary complex of VIII, dorsal & PO & Preoptic area \\
& acoustic nucleus & Pr & Principal toral nucleus \\
DMv & Dorsal medullary complex of VIII, ventral & PSB & Perisolitary band \\
& vestibular division & SC & Spinal cord \\
Ea & Anterior entopeduncular nucleus & SIR & Superficial isthmal reticular nucleus \\
Ep & Posterior entopeduncular nucleus & SO & Superior olive \\
Hd & Dorsal hypothalamus & Tel & Telencephalon \\
Hv & Ventral hypothalamus & TP & Posterior tuberculum \\
Ip & Interpeduncular nucleus & V & Ventral thalamus \\
L & Lateral thalamic nucleus & III & Oculomotor nucleus \\
Lm & Laminar toral nucleus & IV & Trochlear nucleus \\
LP & Lateral pallium & VII & Facial motor nucleus \\
LR & Lateral reticular formation & XII & Hypoglossal nucleus \\
MP & Medial pallium & $4,6,8$ & Tectal cell laminae
\end{tabular}

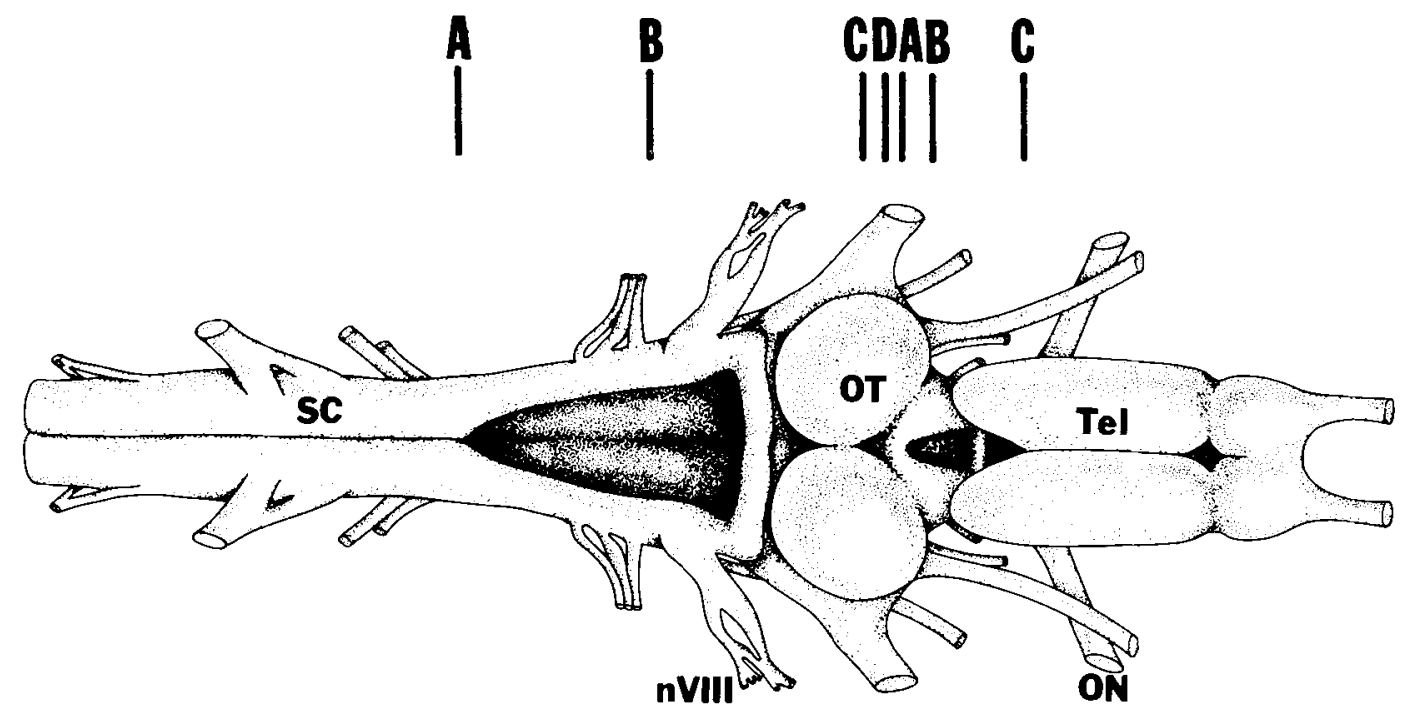

Fig. 1. Dorsal view of the Rana catesbeiana brain. Levels (left to right) A through D and A through C correspond to levels charted in Figure 2 and Figure 3 respectively.

clei to decussate and enter a small ventral fiber bundle which ascended to become continuous with the bundle forming in the olive. An occasional HRP-positive cell was seen in the lateral reticular formation beneath the perisolitary band, and infrequently at other levels throughout the medulla bilaterally. Medullary reticular cells were most numerous at olivary levels.

A greater number of HRP-positive reticular cells were present at tegmental levels. The majority of these cells were located in a superfi- cial column extending from the isthmus to the diencephalic-mesencephalic junction. Opdam et al. ('76) termed the caudal three-quarters of this column the superficial isthmal reticular nucleus; the rostral portion, which contains larger, more scattered cells, is the nucleus profundus mesencephali. Filled cells were more common in the superficial isthmal nucleus (Fig. 2C) and were present bilaterally, with more cells on the ipsilateral side. Occasional cells were seen in nucleus profundus mesen- 

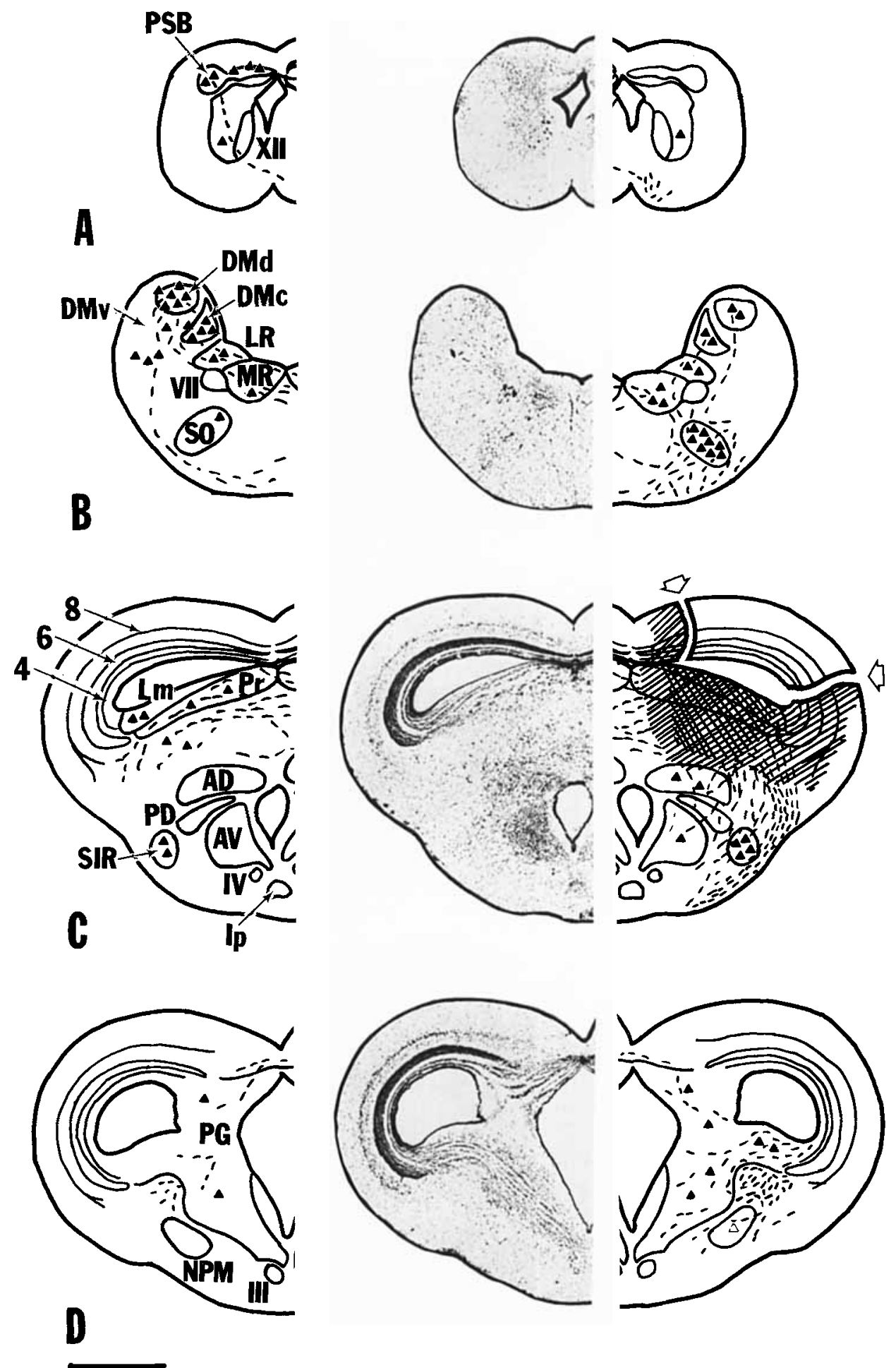

Fig. 2. Results of toral HRP injections. High-contrast photograph of a transverse section from a standard cresyl violetstained series is flanked by line drawings showing the distribution of HRP-positive cells (filled triangles) and fibers (dashed lines) ipsilateral (right) and contralateral (left) to the injection site. Open triangles mark areas where HRP-positive cells were occasionally seen but could not be unequivocally identified as toral afferents. Area of the ipsilateral tectum in level $\mathrm{C}$ marked by open arrows was removed by aspiration prior to the toral injection. Cross-hatched area shows dense injection core surrounded by zone of lighter staining. Calibration bar equals $1 \mathrm{~mm}$. 
WALTER WILCZYNSKI


Fig. 3. Continuation of chartings shown in Figure 2. 

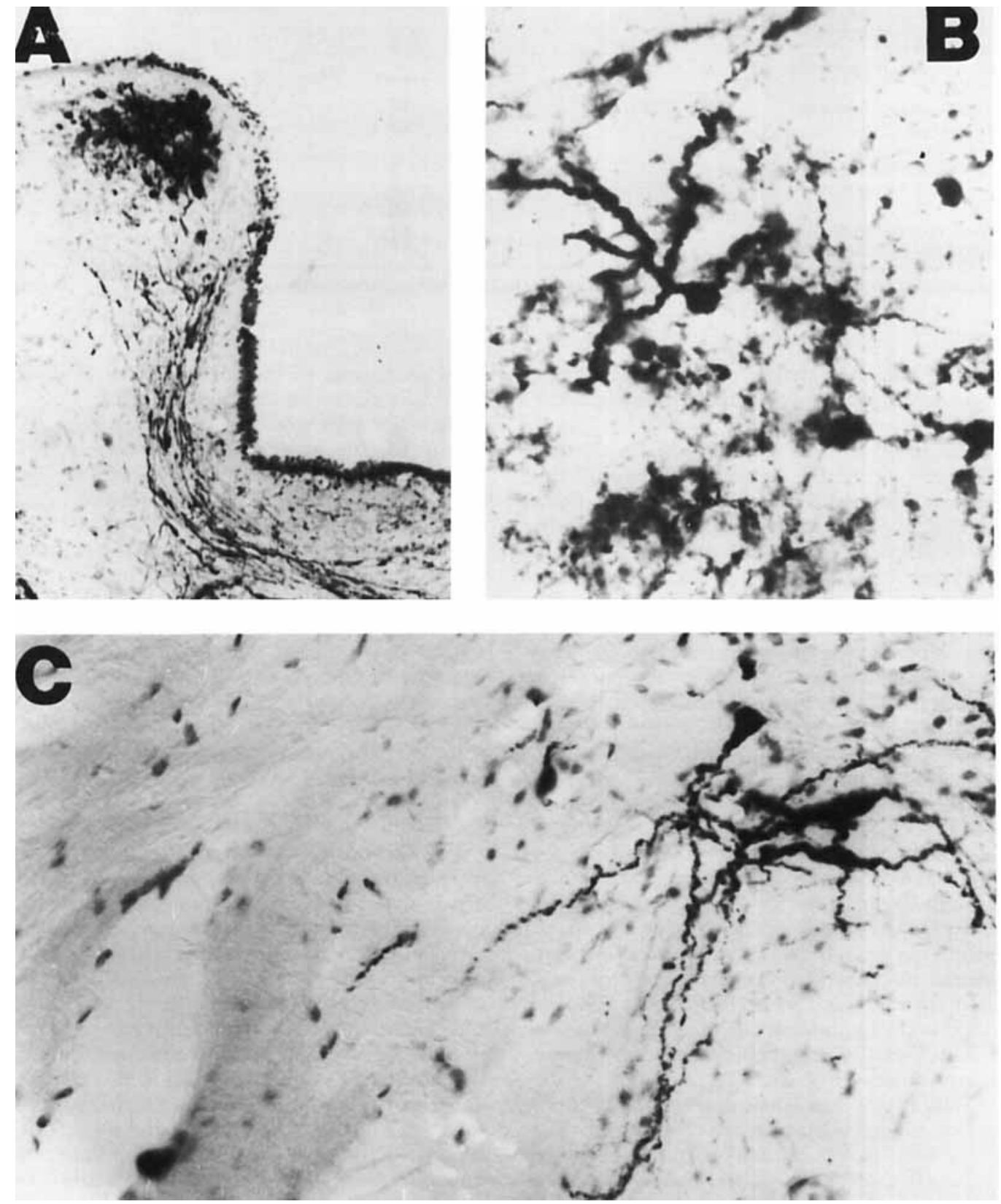

Fig. 4. Photomicrographs of HRP-positive cells following toral HRP injection. A. Densely packed HRP-positive cells in the dorsal acoustic nucleus contralateral to a toral HRP injection. Note the HRP-positive fibers streaming ventrally to cross and join the lateral lemniscus. B. High-power photomicrograph of an HRP-positive cell and fibers in the superior olive ipsilateral to a toral HRP injection. C. HRP-positive cells at the ventral border of the vestibular division of the eighth nerve nuclei contralateral to a toral HRP injection. Fascicles of the eighth nerve are apparent at the left of the photograph. 
TABLE 1. Distribution of HRP-positive cells in medullary nuclei at olivary levels in three large toral HRP injections ${ }^{1}$

\begin{tabular}{|c|c|c|c|}
\hline Nucleus & Ipsilateral & Contralateral & Total \\
\hline Superior olive & 565 & 5 & 570 \\
\hline \multicolumn{4}{|l|}{$\begin{array}{l}\text { Dorsal medullary complex } \\
\text { of VIII }\end{array}$} \\
\hline Dorsal acoustic nucleus & 18 & 96 & 114 \\
\hline Nucleus caudalis & 23 & 95 & 118 \\
\hline \multicolumn{4}{|l|}{ Ventral division } \\
\hline Magnocellular cells & 1 & 4 & 5 \\
\hline Ventral bipolar cells & 4 & 27 & 31 \\
\hline Total & 46 & 222 & 268 \\
\hline Medial reticular formation & 44 & 7 & 51 \\
\hline Lateral reticular formation & 17 & 20 & 37 \\
\hline
\end{tabular}

'The total number of cells as well as the numbers ipsilateral and contralateral to the injection are shown.

cephali, but the number varied directly with the extent of tectal involvement in the injection site.

HRP-positive cells were present in the contralateral principal, laminar, magnocellular, and commissural toral nuclei (Fig. 2C). Filled fibers interconnected the two sides by crossing the toral midline and spreading over all toral areas except the laminar nucleus. Cells were of course present in the ipsilateral tectum after both dorsal and ventral toral injections. However, since dorsal injections introduced HRP directly into the tectum, and since ventral injections invariably spread to the tegmentum, to which the tectum projects (Rubinson, '68), it is impossible to ascribe tectal cell filling to tectotoral interconnections.

HRP-positive cells and fibers were distributed throughout all ipsilateral toral areas not specifically included in the injection site. Filled fibers fanned out rostrally from the torus through the ipsilateral ventral pretectal gray and cell-free area beneath it, but were most prominent immediately ventral to the rostral laminar nucleus. HRP-positive cells were scattered throughout the pretectal gray, concentrated in the ipsilateral ventral region, but also present dorsally and, occasionally, on the contralateral side (Fig. 2D).

Filled fibers continued into the ventral pretectum, where HRP-positive cells were consistently seen in the ventral part of the lateral nucleus (Fig. 3A). The filled ventral lateral nucleus cells were only present after HRP injections which involved the torus. Similarly, HRP-positive cells were present in the dorsal lateral nucleus only after injections involving the optic tectum. A few HRP-positive cells were also apparent in the posterior nucleus after either tectal or toral injections, but they were most numerous in the control cases in which HRP was placed in the tegmentum.

No other HRP-positive cells were seen consistently in the dorsal thalamus. However, cells were occasionally filled in the posterior tuberculum, ventral hypothalamus, and the caudal suprachiasmatic preoptic area, all ipsilateral to the injection site. These cells were most prominent after large injections which invariably involved the tegmentum.

Finally, a few HRP-positive cells were consistently seen in the ipsilateral anterior entopeduncular nucleus and in this area's dorsomedial extension, which lies interposed between the lateral and medial parts of the amygdala (Fig. 3C). No other telencephalic area contained HRP-positive cells.

\section{Toral efferents}

The ascending toral pathways (Neary, '74) were filled with HRP-positive fibers after all toral injections. These fibers ascended ventrally adjacent to the rostral torus and pretectal gray (Fig. 2D). At pretectal levels this ascending bundle moved medially, crossed the ventral lateral nucleus, and entered the caudal pole of the central nucleus to distribute throughout it (Fig. 3A,B). A small bundle remained in a ventrolateral position. Fibers left this tract and entered the central nucleus throughout its length. This ascending bundle eventually crossed in the postoptic decussation to assume an equivalent position contralaterally. The contralateral component was difficult to trace, although a few fibers appeared to enter the contralateral central nucleus as described by Neary ('74).

Some of the filled fibers in the tract between the superior olive and torus may have been descending toral efferents as Röthig ('27) 
claimed. In fact this is likely since some HRPpositive fibers could be followed in a caudal continuation of this bundle at least to upper cervical spinal cord levels. In any event, all of the HRP-positive fibers remained ipsilateral to the injection with the exception of the backfilled contralateral dorsal medullary complex and perisolitary band fibers, which crossed at olivary and obex levels respectively to join the ipsilateral tract.

\section{DISCUSSION}

Three sensory systems, auditory, vestibular, and somatosensory, innervate the ranid torus semicircularis. Ascending auditory inputs contribute the major share. This auditory information arises bilaterally from both recognized brainstem auditory areas: the dorsal medullary complex of VIII and the superior olive. This corroborates earlier findings (Fuller and Ebbesson, '73; Rubinson and Skiles, '75).

The dorsal acoustic nucleus and nucleus caudalis of Opdam et al. ('76) supply the preponderance of input from the eighth nerve nuclei. No physiological data are available to determine whether these nuclei are functionally different, or in fact whether the nucleus caudalis is an auditory or vestibular nucleus. The small input from the ventral division of the eighth nerve nuclei is most likely vestibular, since Skarf ('77) found vestibular responses in the "subtectum" of frogs. However, it should be noted that Moffat and Capranica ('76) found the toad's saccule to respond to high-intensity sound, and axons of this organ innervate the ventral division (Gregory, '72).

Additional auditory input arises from the superior olive. The olivotoral pathway is almost completely uncrossed. This, coupled with the olive's bilateral input from the eighth nerve nuclei (Fuller and Ebbesson, '73) suggests that the unitary anuran superior olive is most similar to the mammalian medial superior olive (MSO) (Stotler, '53; Warr, '66; Strominger and Strominger, '71; Strominger et al., '77; Elverland, '78; Adams, '79). Rubinson ('68) reached the same conclusion for different reasons. The presence of an MSO homolog and the absence of an obvious lateral superior olive (LSO) in anurans is consistent with the type of auditory information anurans process. The mammalian MSO appears to mediate auditory localization based on interaural comparisons while the LSO is involved in processing complex frequency information, including perhaps localization based on complex binaural frequency integration (Masterton and Diamond, '67; Moore and
Moore, '71). In anurans, complex frequency processing may be limited by the auditory system's strict peripheral filtering and relatively low-frequency tuning (Frishkopf et al., '68; Capranica, '76). However, other interaural comparisons for sound localization remain important (Feng and Capranica, '76, '78).

The eighth nerve nuclei project mainly to the contralateral torus while the olivary inputs ascend ipsilaterally. Since the dorsal medullary complex also projects to the contralateral superior olive (Grofova and Corvaja, '72; Fuller and Ebbesson, '73), this arrangement organizes the toral auditory input into two parallel channels, with the majority of information derived from the contralateral ear. Similar parallel channels are present in other tetrapods (Barnes, et al.,' 43; Foster and Hall, '78; Adams, '79). Thompson and Masterton suggest that in cats the collicular afferents from the cochlear nuclei determine the initial direction of head turning, while the olivary input controls the final accuracy of the orientation. The anuran's parallel auditory channels might act in a similar cascade of increasing precision.

Additional input reaches the torus from the presumed somatosensory obex region which Neary and Wilczynski ('77a) termed the perisolitary band. Both the lateral trigeminal portion and the medial area thought homologous with mammalian dorsal colomn nuclei project to the torus, and in fact Comer and Grobstein ('79) demonstrated a gross topographic map in the torus with separate head and body representations. Ebbesson ('76) and Neary and Wilczynski (unpublished observations) have also found a spinal cord projection to the torus which passes through the magnocellular nucleus to the laminar and principal nuclei above it. Toral HRP injections have failed to consistently visualize the responsible spinal cord cells. A few rostral cord cells were filled after large injections which spread to substantial portions of the tegmentum, but since the spinal cord also projects to the tegmentum (Hayle, '73; Ebbesson, '76) interpretations are complicated.

The toral somatosensory input may serve two very different functions. First, it may function as a body map underlying the auditory input to coordinate body position during auditory localization, as suggested to be the case in mammals (Aitkin et al., '78). Such congruent maps in the mammalian superior colliculus (Dräger and Hubel, '76; Stein et al., '76; Finlay et al., '78) and iguanid optic tectum (Gaither and Stein, '79) are thought to mediate a similar process during visual orientation. Second, Comer and 
Grobstein ('79) report that while the middle torus has both auditory and somatosensory activity, the lateral torus is strictly sensitive to tactile stimulation. This paratoral area might represent a "somatosensory tectum" mediating tactile orientation, which Comer ('80) has shown is controlled by the torus.

Other ascending toral input arises from the ill-defined reticular areas of the medulla. Most HRP-positive reticular cells lay around the medullary auditory centers, but whether they receive any auditory input on distal dendrites or via the arcuate and commissural fibers running through them is a matter for speculation. The tegmental reticular areas also project to the torus. The superficial isthmal reticular nucleus (SIR) contains the most HRP-positive cells. These are present bilaterally, with more ipsilaterally, throughout its length.

Both rostral and caudal halves of the SIR project to the torus, but their inputs are very different. Descending striatal and anterior entopeduncular fibers terminate massively in the rostral half of the nucleus (Wilczynski and Northcutt, '79b). By contrast, the ascending auditory inputs pass through the caudal half, but rostrally move above it. The SIR of Opdam et al. ('76) may not be a homogeneous structure, but rather a rostral nucleus tied into a descending basal ganglia system and a caudal nucleus closely related to ascending and descending auditory pathways. Röthig ('27) and later Larsell ('34) described scattered cells interstitial to the ascending auditory fibers which Röthig at least considered homologous to the mammalian nuclei of the lateral lemniscus. These cells appear to coincide with the caudal SIR. Nevertheless, without physiological evidence caution must be exercised in assigning this structure to the auditory system since it is not certain that any of the auditory fibers passing through it actually terminate there.

The torus receives descending input from forebrain centers not generally considered sensory structures. One of these is the pretectum. Pretectal inputs to the torus closely mirror those to the tectum (Trachtenberg and Ingle, '74; Wilczynski and Northcutt,'77). The lateral nucleus projects to both, with dorsal areas terminating in the tectum and ventral areas in the torus. The more medial posterior nucleus clearly projects to the tectum and may also project to the torus, although its main output travels to the tegmentum.

The pretectum is a powerful modulator of tectal visuomotor functions (Ewert, '70; Ingle,
'70, '73a). Dorsal portions of the lateral nucleus most likely exert this control (Trachtenberg and Ingle, '74; Wilczynski and Northcutt, '77). An obvious, and testable, hypothesis is that the ventral lateral nucleus similarly modulates the torus. Ingle ('73b, '77) believes the pretectum to control stationary barrier detection and avoidance directly. The posterior nucleus, with its heavy tegmental projections, might provide the nontectal route through which barrier avoidance is mediated. Moreover, if the posterior nucleus does serve this function, it would not be surprising to find ancillary projections reaching midbrain roof areas mediating orientation and approach behavior.

Autoradiographic studies have shown that both the hypothalamus (Neary and Wilczynski, '77b) and preoptic area (unpublished observations) project to the midbrain roof. Input from these areas overlap in the toral laminar nucleus. HRP injections in the torus have failed to provide an adequate visualization of the exact cells of origin. Large toral injections which spread to the tegmentum have occasionally shown filled cells in the ventral hypothalamus, posterior tuberal region, and caudal suprachiasmatic preoptic area. However, HRP-positive cells are present in these same areas after tegmental HRP injections, and therefore it is unclear whether all these areas project to both torus and tegmentum, or whether there is any segregation.

The periventricular layers of the midbrain roof are topographically identical to the mammalian central gray, which receives afferents from several hypothalamic and preoptic cell groups (Saper et al., '76; Swanson, '76; Grofova et al., '78). Similar projections are apparent in birds (Berk and Butler, '77). Therefore, basal forebrain input to the periventricular midbrain roof is not surprising. What is significant, however, is the close association of these inputs with midbrain sensory, and especially auditory, centers since steroid hormone concentrating cells are present in the basal forebrain as well as the toral laminar nucleus (Kelly et al., '75; Morrell et al., '75; Kelley et al., '78). Moreover, at least the preoptic area has been implicated in mating behaviors (Schmidt, '68, '69; Wada and Gorbman, '77). Perhaps these areas interact to control the seasonal gating of mating behavior, for which audition is so important.

The anterior entopeduncular nucleus is the final source of descending toral inputs. This nucleus lies in part around the lateral forebrain 
bundle and in part extends dorsomedially between the two parts of the amygdala. Northcutt (74) considered the anterior entopeduncular nucleus a caudal continuation of the ventral striatum and therefore a subpallial structure. This input is particularly significant in that it is the only direct telencephalic projection to the midbrain roof. Moreover, the anterior entopeduncular nucleus receives a heavy, bilateral striatal input and thereby acts in the multiple feedback pathways by which the striatum, the major telencephalic auditory area (Wilczynski and Northcutt, '79a; Mudry and Capranica, '80), can influence the torus. These indirect telencephalic inputs also reach the torus via tegmental relays involving the superficial isthmal reticular nucleus and tegmental fields, and via pretectal relays involving the lateral and possibly posterior nuclei (Wilczynski and Northcutt, '79b).

No pallial areas considered homologous with mammalian or reptilian cortex contribute to these indirect relays, nor, in fact, do they project directly to the torus. Identical results based on anterograde degeneration techniques were obtained by Halpern ('72) in Rana and Kokoros (73) in Bufo. Similarly, these authors, and Wilczynski and Northcutt ('77), reported an absence of pallial input to the tectum. Kokoros and Northcutt ('77) found no pallial input to the midbrain roof in Ambystoma, but did see a sparse projection from the caudolateral telencephalic wall, a position similar to that occupied by the anuran anterior entopeduncular nucleus. The amphibian condition is strikingly different from the mammalian, where extensive cortical inputs reach the inferior colliculus (Diamond et al., '69; Fitzpatrick and Imig, '78). The functional implications of this major connectional difference have never been adequately investigated.

The results described demonstrate the rich and complex innervation of the anuran torus. In this general regard, and in many specific ways, the toral inputs are similar to the optic tectum's afferents. The hodological parallels between the two structures suggest that, rather that acting as a simple relay nucleus, the torus functions in audition much the same as the optic tectum functions in vision-that is, as a sensory processing center which is modulated by a number of nonsensory inputs and whose function is to localize and program appropriate, reflexive motor responses. Physiological and behavioral studies will be necessary to determine if this interpretation is correct.

\section{ACKNOWLEDGMENTS}

Results presented above were submitted to the University of Michigan in partial fulfillment of the requirements for the degree of Doctor of Philosophy in the Neurosciences. I wish to thank Dr. R. G. Northcutt for his guidance and support throughout the course of this study; he, with $H$. Zakon, provided valuable comments on the manuscript. This work was supported by predoctoral fellowship 5 T32 MH14279 and a Rackham Dissertation Grant, and by PHS grant 1 R01 EYO 2485 to R. G. Northcutt, Div. Biol. Sci., University of Michigan.

\section{LITERATURE CITED}

Adams, J.C. (1979) Ascending projections to the inferior colliculus. J. Comp. Neurol. 183:519-538.

Aitkin, L.M., H. Dickhaus, W. Schult, and M, Zimmerman (1978) External nucleus of inferior colliculus: Auditory and spinal somatosensory afferents and their interactions. J. Neurophysiol, 41:837-847.

Ariëns-Kappers, C.U., G.C. Huber, and E.C. Crosby (1960) The Comparative Anatomy of the Nervous System of Vertebrates, Including Man. Vol. II, New York: Hafner.

Barnes, W.T., H.W. Magoun, and S.W. Ranson (1943) The ascending auditory pathway in the brain stem of the monkey. J. Comp. Neurol. 79:129-152.

Berk, M.L., and A.B. Butler (1977) Efferent projections of the preoptic-hypothalamic regions in the pigeon, Columba livia, as demonstrated by the autoradiographic technique. Anat. Rec. 187:537.

Blair, W.F. (1958) Mating call in the speciation of anuran amphibians. Am. Naturalist 92:27-51.

Capranica, R.R. (1976) Morphology and physiology of the auditory system. In R. Llinas and W. Precht (eds): Frog Neurobiology. Berlin: Springer-Verlag, pp. 551-575.

Carey, C.L., and D.B. Webster (1971) Ascending and descending projections of the inferior colliculus in the kangaroo rat (Dipodomys merriami). Brain Behav. Evol 4:401-412.

Colman, D.R., F. Scalia, and E. Cabrales (1976) Light and electron microscopic observations on the anterograde transport of horseradish peroxidase in the optic pathway in the mouse and rat. Brain Res. 102:156-163.

Comer, C. (1980) The Neural Basis of Tactually Elicited Prey Acquisition Behavior in the Leopard Frog, Rana pipiens. Doctoral Thesis, University of Chicago.

Comer, C., and P. Grobstein (1979) Organization of somatosensory input to the midbrain of the frog. Neurosci. Abst. 5:140.

Diamond, I.T., E.G. Jones, and T.P.S. Powell (1969) The projection of the auditory cortex upon the diencephalon and brainstem in the cat. Brain Res. 15:305-340.

Dräger, U.C., and D.H. Hubel (1976) Topography of visual and somatosensory projections to mouse superior colliculus. J. Neurophysiol. 39:91-101.

Ebbesson, S.O.E. (1976) Morphology of the spinal cord. In R. Llinas and W. Precht (eds): Frog Neurobiology. Berlin: Springer-Verlag, pp. 679-706.

Elverland, H.H. (1978) Ascending and intrinsic projections of the superior olivary complex in the cat. Exp. Brain Res. 32: 117-134.

Ewert, J.-P. (1970) Neural mechanisms of prey catching and avoidance behavior in the toad (Bufo bufo, L.), Brain Behav. Evol. 39:871-881. 
Feng, A.S., and R.R. Capranica (1976) Sound localization in anurans. I. Evidence of binaural interaction in dorsal medullary nucleus of bullfrogs (Rana catesbeiana). J. Neurophysiol. 39:871-881

Feng, A.S., and R.R. Capranica (1978) Sound localization in anurans. II. Binaural interaction in superior olivary nucleus of the green tree frog (Hyla cinerea). J. Neurophysiol. 41:43-54.

Finlay, B.L., S.E. Schneps, K.G. Wilson, and G.E. Schneider (1978) Topography of visual and somatosensory projections to the superior colliculus of the golden hamster Brain Res. 142:223-235.

Fitzpatrick, K.A., and T.J. Imig (1978) Projections of auditory cortex upon the thalamus and midbrain in the owl monkey. J. Comp. Neurol. 177:537-556.

Foster, R.E., and W.C. Hall (1978) The organization of central auditory pathways in a reptile, Iguana iguana. J. Comp. Neurol. 178:783-832.

Frishkopf, L.S., R.R. Capranica, and M.H. Goldstein (1968) Neural coding in the bullfrog's auditory system - a teleological approach. Proc. IEEE 56:969-980.

Fuller, P.M., and S.O.E. Ebbesson (1973) Projections of the primary and secondary auditory fibers in the bullfrog (Rana catesbeiana). Proc. Soc. Neurosci.:333.

Gaither, N.S., and B.E. Stein (1979) Reptiles and mammals use similar sensory organizations in the midbrain. Science 205:595-597.

Graham, R.C., and M.J. Karnovsky (1966) The early stage of absorption of injected horseradish peroxidase in the proximal tubules of mouse kidney: Ultrastructural cytochemistry by a new technique. J. Histochem. Cytochem. 14: 291-302.

Gregory, K.M. (1972) Central projections of the eighth nerve in frogs. Brain Behav. Evol. 5:70-88.

Grofova, I., and N. Corvaja (1972) Commissural projection from the nuclei of termination of the VIIIth cranial nerve in the toad. Brain Res. 42:189-195.

Grofova, I., O.P. Ottersen, and E. Rinvik (1978) Mesencephalic and diencephalic afferents to the superior colliculus and periaqueductal gray substance demonstrated by retrograde axonal transport of horseradish peroxidase in the cat. Brain Res. 146:205-220.

Halpern, M. (1972) Some connections of the telencephalon of the frog, Rana pipiens. Brain Behav. Evol. 6:42-68.

Hayle, T.H. (1973) A comparative study of spinal projections to the brain (except cerebellum) in three classes of poikilothermic vertebrates. J. Comp. Neurol. 149:463-476.

Ingle, D. (1970) Visuomotor functions of the frog optic tectum. Brain Behav. Evol. 3:57-71.

Ingle, D. (1973a) Disinhibition of tectal neurons by pretectal lesions in the frog. Science 180:422-424.

Ingle, D. (1973b) Two visual systems in the frog. Science 181:1035-1055

Ingle, D. (1977) Detection of stationary objects by frogs (Rana pipiens) after ablations of optic tectum. J. Comp Physiol. Psychol. 91:1359-1364.

Kelley, D.B., I. Lieberberg, B.S. McEwen, and D.W. Pfaff (1978) Autoradiographic and biochemical studies of steroid hormone-concentrating cells in the brain of Rano pipiens. Brain Res. 140:287-305.

Kelley, D.B., J.I. Morrell, and D.W. Pfaff (1975) Autoradiographic localization of hormone-concentrating cells in the brain of an amphibian, Xenopus laevis. I. Testosterone. J. Comp. Neurol. 164:47-62.

Kokoros, J.J. (1973) Efferent Connections of the Telencephalon in the Toad, Bufo bufo, and the Tiger Salamander, Ambystoma tigrinum. Doctoral Thesis, Case Western Reserve University.

Kokoros, J.J., and R.G. Northcutt (1977) Telencephalic efferents of the tiger salamander, Ambystoma tigrinum tigrinum (Green). J. Comp. Neurol. 173:613-628.

Larsell, $O$. (1934) The differentiation of the peripheral and central acoustic apparatus in the frog. J. Comp. Neurol $60: 473-527$.

Loftus-Hills, J.J. (1971) Neural correlates of acoustic behavior in the Australian bullfrog, Limnodynastes dorsalis (Anura: Leptodactylidae). Z. Vergl. Physiologie 74:140152.

Masterton, B., and I.T. Diamond (1967) Medial superior olive and sound localization. Science 155:1696-1697.

Moffat, A.J.M., and R.R. Capranica (1976) Auditory sensitivity of the saccule in the American toad (Bufo americanus). J. Comp. Physiol. 105:1-8.

Moore, J.K., and R.Y. Moore (1971) A comparative study of the superior olivary complex in the primate brain. Folia Primatol. (Basel) 16:35-51.

Moore, R.Y., and J.M. Groldberg (1966) Projections of the inferior colliculus in the monkey. Exp. Neurol. 14:429 438.

Morrell, J.I., D.B. Kelley, and D.F. Pfaff (1975) Autoradiographic localization of hormone-concentrating cells in the brain of an amphibian, Xenopus laevis. II. Estradiol. J. Comp. Neurol. 164:63-78.

Mudry, K.M., and R.R. Capranica (1980) Evoked auditory activity within the telencephalon of the bullfrog (Rana catesbeiana). Brain Res. 182:303-311.

Neary, T.J. (1974) Diencephalic efferents of the torus semicircularis in the bullfrog, Rana catesbeiana. Anat. Rec. 178:425.

Neary, T.J., and W. Wilczynski (1977a) Ascending thalamic projections from the obex region in ranid frogs. Brain Res. 138:529-533.

Neary, T.J., and W. Wilczynski (1977b) Autoradiographic demonstration of hypothalamic efferents in the bullfrog, Rana catesbeiana. Anat. Rec. 187:665.

Northcutt, R.G. (1974) Some histochemical observations on the telencephalon of the bullfrog, Rana catesbeiana Shaw. J. Comp. Neurol. 157:379-390.

Opdam, P., M. Kemali, and R. Nieuwenhuys (1976) Topological analysis of the brain stem of the frogs Rana esculenta and Rana catesbeiana. J. Comp. Neurol. 165:307-332.

Potter, H.D, (1965) Patterns of acoustically evoked discharges of neurons in the mesencephalon of the bullfrog. J. Neurophysiol. 28:1155-1184.

Röthig, P. (1927) Beiträge zum studium des Zentralnerven systems der Wirbeittiere. XI. Über die Faserzüge im Mittelhirn, Kleinhirn und der Medulla oblongata der Urodelen und Anuran. Zeitschr. für mikros. Anat. Forsch. 10:381-472.

Rubinson, K. (1968) Projections of the tectum opticum of the frog. Brain Behav. Evol 1:203-232.

Rubinson, K, and M.P. Skiles (1975) Efferent projections of the superior olivary nucleus in the frog, Rana catesbeiana. Brain Behav. Evol. 12:151-160.

Saper, C.B., L.W. Swanson, and M.W. Jowen (1976) The efferent connections of the ventromedi.al nucleus of the hypothalamus of the rat. J. Comp. Neurol. 168:409-442.

Schmidt, R.S. (1968) Preoptic activation of frog mating be havior. Behavior 30:239-257.

Schmidt, R.S. (1969) Preoptic activation of mating call orientation in female anurans. Behavior 35:114-127.

Skarf, B. (1977) Natural vestibular stimulation: Effect on neural activity in the mesencephalon of the frog. Neurosci. Abst. 3:546.

Stein, B.E., B. Magalhaes-Castro, and L. Kruger (1976) Relationship between visual and tactile representations in cat superior colliculus. J. Neurophysiol. 39:401-419.

Stotler, W.A. (1953) An experimental study of the cells and connections of the superior olivary complex of the cat. J. Comp. Neurol. 98:401-432.

Strominger, N.L., L.R. Nelson, and W.J. Dougherty (1977) Second order auditory pathways in the chimpanzee. J. Comp. Neurol. 172:349-366.

Strominger, N.L., and A.I. Strominger (1971) Ascending 
brain stem projections of the anteroventral cochlear nucleus in the rhesus monkey. J. Comp. Neurol. 143:217 242.

Swanson, L.W. (1976) An autoradiographic study of the efferent connections of the preoptic region in the rat. $J$ Comp. Neurol. 167:227-256.

Thompson, G.C., and R.B. Masterton (1978) Brain stem auditory pathways involved in reflexive head orientation to sound. J. Neurophysiol. 41:1183-1202.

Trachtenberg, M.C., and D. Ingle (1974) Thalamo-tectal projections in the frog. Brain Res. 79:419-430.

Wada, M., and A. Gorbman (1977) Mate calling by electrical stimulation in freely moving leopard frogs, Rana pipiens. Horm. Behav. 9: 141-149.
Warr, W.B. (1966) Fiber degeneration following lesions in the anterior ventral cochlear nucleus. Exp. Neurol. 14: 453-474.

Wilezynski, W. (1978) Torus semicircularis afferents in the bullfrog, Rana catesbeiana. Neurosci. Abst. 4:103.

Wilczynski, W., and R.G. Northcutt (1977) Afferents to the optic tectum of the leopard frog: An HRP study. J. Comp. Neurol. 173:219-229.

Wilczynski, W., and R.G. Northcutt (1979a) An HRP study of the anuran striatum. Anat. Rec. 193:721.

Wilczynski, W, and R.G. Northcutt (1979b) Striatal efferents in the bullfrog, Rana catesbeiana. Neurosci. Abst. $5: 157$. 